\title{
LA CIRCULACIÓN DE CONOCIMIENTOS Y LA DISCUSIÓN SOBRE LA INFANCIA: ANÁLISIS DESDE LA REVISTA EDUCACIÓN, 1933 - 1935*
}

\author{
LEONARDO RAFAEL LUNA ESLAVA ${ }^{1}$ \\ CORPORACIÓN UNIVERSITARIA IBEROAMERICANA, COLOMBIA
}

\author{
Recibido: 8 de Abril de 2016 \\ Aprobado: 13 de Junio de 2016 \\ Para referenciar este artículo: \\ Luna Eslava, L. (2016). La circulación de conocimientos y la discusión sobre la infancia: análisis desde la revista educación, \\ 1933 - 1935. Revista Iberoamericana de Psicología: Ciencia y Tecnología, 9 (1), 33-44
}

\begin{abstract}
Resumen
El artículo presenta los resultados de un análisis histórico - cultural sobre la construcción de la categoría social de infancia en Colombia a partir del corpus documental de la revista Educación, puesta en circulación entre los años 1933 y 1935 por la Facultad de Ciencias de Educación de la Universidad Nacional de Colombia. La investigación se realizó desde la perspectiva de análisis de Chartier obteniendo como resultado la identificación de discursos experimentales provenientes de la psicología moderna como formas de razonamiento para abordar y pensar a los infantes, discursos que eran promovidos por grupos específicos de intelectuales de la época. Los discursos experimentales se presentan como los encargados de ayudar a conservar la institucionalidad por medio de la transmisión a los infantes de la primera parte del siglo XX de nociones de "orden" básicas. Así también se encuentra una marcada predilección por el estudio de lo orgánico y fisiológico sobre lo subjetivo. Todos estos aspectos permiten entender la ruptura entre formas de conocimiento y caracterizar la particularidad de este grupo poblacional. Los resultados incluyen también la identificación y análisis de diferentes patrones en el habla de grupos intelectuales e instituciones, lo cual permite rastrear el establecimiento de formas de pensamiento que dieron lugar a acciones y actitudes en torno a este grupo particular. La investigación finaliza refiriéndose a la imagen social, rupturas y cambios en relación a lo que se entendía por "infancia" a principios del siglo XX.

Palabras clave: Infancia, ciencias sociales, conocimiento científico, formas de razonamiento, Revista Educación, psicología experimental.
\end{abstract}

\section{THE CIRCULATION OF KNOWLEDGE AND THE DISCUSSION ON CHILDHOOD: ANALYSIS FROM THE EDUCATION JOURNAL, 1933-1935}

\begin{abstract}
This paper shows the results of a historical-cultural analysis of the construction of childhood as a social category in Colombia. This analysis is based on the revision of a documented corpus from a Journal called Educación, put into circulation by the Education Sciences Faculty of the National University of Colombia between 1933 and 1935. The research was carried out from an analysis of Chartier perspective, enabling the identification of experimental speech/ discourses that come from modern psychology as forms of reasoning to approach and think about children, speech/ discourses that were promoted by specific groups of intellectuals of the time. Experimental speeches are presented as tools that help preserve the institutionality by means of the transmission of the basic notion of 'order' to children during the first part of the 20th century. A marked predilection for the study of the organic and physiological instead of the subjective, was also found. All these aspects allow for the understanding of a rupture between forms of knowledge,
\end{abstract}

* La presente investigación se realizó en el marco del programa de investigación denominado "el discurso científico de lo social como dispositivo: producción, circulación y recontextualización”, dirigido por el doctor Carlos Jilmar Díaz Soler, programa que busca reflexionar en relación a la circulación de saberes y su implicación en lo cultural, social y político. El programa está inscrito en la línea de investigación poder, política y sujetos de la maestría en investigación social interdisciplinaria de la Universidad Distrital Francisco José de Caldas.

1 Mg. En Investigación Social Interdisciplinaria de la Universidad Distrital Francisco José de Caldas. Psicólogo egresado de la Corporación Universitaria Iberoamericana. Docente Universitario del área de psicología social, investigación cualitativa y ciencias de la Corporación Universitaria Iberoamericana. 
and allow to characterize and highlight the particularity of this specific population group. The results include also the identification and analysis of different patterns in speeches by intellectual groups and several institutions which contributed to disseminate forms of thinking, which brought about particular actions and attitudes around this group. The research points out the social image, rupture and changes of what was considered 'childhood' at the beginning the 20th centuryKey words: Childhood, social science, scientific knowledge, forms of thinking, Revista Educación, experimental psychology.

Este estudio presenta reflexiones sobre las relaciones de poder y el entretejido social y cultural que han ayudado a la organización de la categoría de análisis central del presente informe: la infancia. Buscamos aproximarnos al entendimiento de cómo se ha configurado el conocimiento sobre esta categoría, explorando para ello cuestiones que versan sobre la relación entre las metodologías de enseñanza e instrucción y los discursos de la clase intelectual como grupo social que, en su ejercicio de poder y cambio social, promovió el posicionamiento de un sistema de ideas y principios en el cual se configuró el horizonte de sentido de este grupo poblacional particular.

La investigación se realizó en el contexto del periodo que dio inicio a la República Liberal entre 1930 y 1946. Se tomó como eje central de análisis los discursos de las ciencias sociales que fueron incorporados en la Revista Educación, específicamente las publicaciones realizadas entre 1933 y 1935 en la Universidad Nacional de Colombia. De ahí que la propuesta analítica para el abordaje de la categoría objetivo de esta investigación esté basada en el desarrollo de una perspectiva histórica.

Las preguntas que guiaron el desarrollo de la investigación son las siguientes: ¿Cuáles son las formas de razonamiento que circularon en la revista Educación y que ayudaron a configurar unas imágenes de infancia en Colombia a principios del siglo XX?, ¿Cuáles son los rasgos significativos con los que se presentaba la infancia y que se buscaban consolidar a partir de los conocimientos que circulaban en la revista Educación? y ¿Cuáles son las rupturas que estas formas de razonamiento realizan con el pasado?

Desde estas inquietudes y reflexiones buscamos aportar a la discusión relacionada con la historia de la categoría de infancia en Colombia; contribuyendo a los trabajos adelantados en esta misma línea y que se han acercado a esta población, en particular desde las formas que fue concebida por las disciplinas de las ciencias sociales. Creemos que esta investigación con perspectiva histórica puede contribuir a la comprensión de la manera actual para abordar la infancia, aceptando que las imágenes que hoy en día siguen teniendo cierto consenso en parte de la población, tienen su justificación en procesos culturales de un pasado reciente, que no son naturales, ni evidentes y que finalmente, son las que condicionan la forma en la cual vemos, abordamos y nos comunicamos con los niños, niñas y jóvenes.

El análisis sobre la primera mitad del siglo XX como periodo privilegiado de la investigación, se debe a que este periodo es considerado como el centro de la génesis del sistema educativo moderno en Colombia, sistema en el cual circularon y se institucionalizaron como novedad los saberes científicos experimentales que analizamos, y en donde se propendía la alfabetización y escolarización de los colombianos. Además, es un periodo de transformaciones sustanciales de la sociedad y la economía, industrialización, expansión de la producción del café, apertura al mercado mundial, llegada masiva de capitales extranjeros, urbanización, cristalización de las estructuras sociales y políticas que conforman la Colombia de hoy.

\section{La educación en el contexto de los años 30}

La investigación se realizó teniendo en cuenta dos periodos epistemológicos de los saberes sociales planteados por Oscar Saldarriaga en su trabajo denominado Del oficio de maestro, prácticas y teorías de la pedagogía moderna en Colombia. El periodo previo a la hegemonía liberal de 1930, lo llamaremos modernidad clásica, representada por el método pestalozziano que se basaba en la episteme clásica de la representación para explicar la manera de adquirir el conocimiento por parte de los infantes. El segundo periodo, a partir de 1930, lo denominaremos modernidad experimental, caracterizado por la circulación de textos que privilegiaban el método experimental. El método experimental estaba basado principalmente en la medicina experimental redescubierta por Claude Bernard, en su libro titulado introducción al estudio de la medicina experimental, publicado en 1865.

La modernidad clásica entiende que los objetos se representan como ideas, las ideas son signos de las cosas y las palabras representan el pensamiento, luego estas son signos de las ideas. De aquí se designa que la naturaleza del conocer al modo clásico, consiste en que puede y deben existir signos (imágenes o palabras) en nuestra mente, pero su huella en la memoria sería frágil si no se encuentra ligada a la representación de su objeto. Por lo tanto, la 
experiencia fungía como base del conocimiento (Sáenz, 1997, p. 19-26). El fundamento que señalaba el lenguaje y el conocimiento como representación del universo, se desencadenó en técnicas de aprendizaje basadas en el memorismo y el verbalismo.

De otro lado la ciencia experimental era definida como postulados a priori como hipótesis y axiomas hechos por el investigador, que no necesariamente eran deducidas por la observación, pero cuyos resultados y teorías se iban acumulando en una tradición científica que ponían en entredicho el rol tan radical que el empirismo había otorgado a la experiencia individual. Con el método experimental, se trasciende la experiencia personal del sujeto de conocimiento. Este método "aseguraba" las condiciones objetivas y subjetivas que garantizaban la validez y universalidad del conocimiento, al menos del que pretende ser científico (Saldarriaga, 2003).

No obstante, no hay una separación radical entre el método experimental y el método empírico o experiencial. En cierto sentido, el empirismo da un primer paso hacia el método experimental, este último supera la experiencia en la medida que se funda en el conocimiento de las leyes vitales de fisiología; es a partir de este conocimiento desde donde se puede "dominar" científicamente a la naturaleza viva, conquistarla en beneficio del hombre. Ambos sistemas, si bien eran diferentes, no se eliminaban uno al otro, más bien existía una yuxtaposición; los experimentalistas obtenían de los experiencialistas, o del método empírico, la información que debía ser comprobada y de la cual se podría sacar conclusiones para dar explicaciones a los fenómenos deseados (Saldarriaga,2003).

Ambas tendencias de la modernidad, clásica y experimental, han sido determinantes en la configuración de la imagen de infancia moderna en Colombia. Los saberes sociales modernos empezaron a oscilar desde dos perspectivas epistemológicas, una basada en la episteme de la representación y el sensualismo como fuente del conocimiento -que reconoce un infante "activo" en la adquisición de conocimiento- y una basada en el método deductivo, que al incorporar una nueva explicación de la subjetividad del sujeto a partir de la biología y la fisiología, ayuda a consolidar la idea del infante "activo" y como nuevo sujeto de saber. Sin embargo, y a pesar que desde ambas perspectivas se reconoce en el infante una naturaleza específica y una singularidad, con la modernidad experimental, se establece un movimiento o una mutación en los lenguajes utilizados por los intelectuales modernos, movimiento que es necesario estudiar a partir del análisis de discurso.
La infancia moderna aparece bajo condiciones que definen, con su posibilidad histórica, el dominio de su experiencia y la estructura de su racionalidad. Para indagar las formas de razonamiento, es necesario preguntarnos por el lenguaje, es decir, los discursos que están dirigidos al tema de la niñez y que se constituyen, a su vez, en el marco en el cual los mismos sujetos niños se configuran. El lenguaje es comprendido como aquello que precede a cada niño y lo sucede; es ese continuo flujo en el que se inserta, se suma y se singulariza (Díaz, 2010).

La estructura del discurso que entrará en análisis es dada por las ciencias sociales, entendiendo que es desde ellas que se ha creado un lenguaje que ha ayudado a configurar las ideas que se tienen sobre la infancia. Las ciencias sociales las pensamos como empresas del mundo moderno, basadas en el modelo empírico-experimental, que encontraron en el infante, un nuevo objeto de observación y análisis. Emergieron así la pedagogía moderna y la psicología experimental como disciplinas, que desarrollaron conceptos como el desarrollo, la adolescencia, el aprendizaje, las aptitudes, la inteligencia, entre otras; que ayudaran a entender y dar sentido al infante.

La psicología y la pedagogía como ciencias modernas se definen como tal, sobre todo por su método, así como por su aplicación y utilidad práctica. Tanto las exigencias del método científico experimental, como la búsqueda de la aplicabilidad práctica de los saberes, hacen aparecer una serie de nuevos objetos de discurso y de nuevos conceptos que remplazan las preocupaciones clásicas de la teología, la filosofía, la lógica y la ética; las cuales se tornan invisibles al quedar por fuera, tanto de los alcances del método como del principio de aplicabilidad clara y directa a la vida práctica. El método de los nuevos saberes científicos, en general, es la experimentación y la observación rigurosa y objetiva de la naturaleza y de los actos del ser humano. El énfasis en la utilidad inmediata de los saberes modernos, en la importancia de derivar de éstas técnicas económicas, sociales y pedagógicas, estaría ligado a dos factores principales. En primera instancia, a la nueva imagen del hombre que éstos saberes ayudaron a crear: el hombre como mecanismo de adaptación a las exigencias de la vida natural y social; el hombre activo, productivo, útil. En segundo lugar, a las apremiantes exigencias de un mundo moderno cada vez más complejo, diferenciado y tecnificado (Sáenz, 2004).

Entrada la década del treinta, las universidades empiezan a ser centro de los debates en cuanto a la circulación de los saberes modernos. Estas instituciones eran consideradas como espacios que aún mantenían rezagos de 
los saberes tradicionales, por lo tanto, los intelectuales con ideales modernos buscaban que se transformaran y fueran el espacio privilegiado de la circulación de los saberes experimentales que les ayudara a consolidar las pretensiones de organización estatal que tenían.

Para entender cómo la circulación de saberes sociales experimentales en las universidades se vinculó al proyecto de modernización, es necesario acogernos al concepto de gubernamentalidad de Michael Foucault, entendiéndolo como el conjunto de instituciones, procedimientos, análisis y reflexiones, cálculos y tácticas que han permitido ejercer el poder sobre la población, a partir de unos dispositivos sociales que facilitan la extensión de dicho poder. Para el autor, el gobierno crea una serie de dispositivos que buscan consolidar el control de la población, partiendo desde el conocimiento de la misma, hasta generar procesos de subjetivación que permitan su aprehensión. En este sentido, la población sería el objeto que el gobierno deberá tener en cuenta en sus observaciones, en su saber, para llegar efectivamente a gobernarla de un modo racional e inteligente (Foucault, 1979).

Con la ayuda de la psicología experimental, la pedagogía entra a ser vista como una estrategia fundamental en la administración social del niño. El surgimiento de las nuevas psicologías de solución de problemas, medición y desarrollo del niño, incluyeron distinciones y diferenciaciones que habían de regular, no solo cómo se organizaba la información sobre la escolarización y cómo se describían los problemas de la misma, sino también los sistemas discursivos que incorporaban categorías de desarrollo y futuro, así como de competencia y logro personal. La psicología, como práctica de gubernamentalidad, se introdujo en la escolarización de masas como una tecnología para la reestructuración de la forma en que había que verse a los individuos, definirlos y evaluarlos; se convierte en una tecnología para organizar las didácticas de aula, los materiales de enseñanza y la asignación del tiempo a las asignaturas escolares según lo que los niños tuvieran que aprender.

Para hacer el análisis histórico del pensamiento científico que giró en torno a la infancia, es necesario rastrear los lugares de donde provienen y circularon los mencionados discursos científicos de las ciencias sociales experimentales. Entre estos escenarios se encuentran los corpus documentales especializados que se pusieron en circulación por parte de las instituciones que pretendían monopolizar el conocimiento en Colombia. Al decir que los corpus documentales son unos dispositivos de gubernamentalidad, nos referimos a que estos hacen parte de unas técnicas y de unas instituciones a las que se le atribuyeron la tarea de medir, controlar y corregir a la población. Los libros, textos y revistas permiten una implantación de los cuerpos en el espacio, la distribución de los individuos, la organización jerárquica, la disposición de los centros y de los canales de poder, la definición de sus instrumentos y de sus modos de intervención.

Estos dispositivos, según Foucault, permiten perfeccionar el ejercicio del poder, por medio de la reducción del número de los que lo ejercen, a su vez que multiplica el número de aquello sobre los que se ejerce. Los dispositivos facilitan la intervención a cada instante desde un funcionamiento continuo, son mecanismos que distribuyen, crean desviaciones, series y combinaciones, hacen visibles, registran diferencias y comparan (Foucault, 1976). Los corpus documentales se pueden entender como formas de gobernar.

De igual manera, entendemos los corpus documentales como sistemas de producción, es decir, es un objeto semiótico, como un espectro interrelacionado de signos que sólo puede ser develado desde marcos epocales y ser asociado o emparentado con otros testimonios. Esto surge debido a que en los años setenta, un conjunto de reflexiones apuntaron a señalar que el documento escrito no era un objeto simplemente destinado a generar representaciones con base en unas estructuras significativas, sino que éste es una producción social, provocada eficientemente para arbitrar relaciones de fuerza. Para lo cual es necesario recuperar el orden retórico del texto, pues era por intermedio de estas composiciones en el lenguaje, que se transmitían las pretensiones del poder, de la política y de unas fuerzas hegemónicas (Serna, 2007).

Este es el caso de la revista Educación, publicada entre 1933 y 1935. La revista era utilizada como órgano de difusión de la Facultad de Ciencias de la Educación de la Universidad Nacional de Colombia. En las páginas de ésta revista se evidencia una marcada preocupación por temas relacionados con la infancia, principalmente por la infancia popular que era descrita en "situación de riesgo" y que debería tener una indispensable "atención del Estado", quien a su vez, dentro de su política de gobierno, debería facilitar un número de escuelas con pedagogías particulares que promovieran su protección; así como la formación de maestros para su "adecuado" cuidado y formación, pero sobre todo, se discutía la necesidad de formar una "conciencia nacional" alrededor de la importancia de este periodo de la vida, tanto para los individuos como para la sociedad. 


\section{Método}

\section{Tipo de estudio}

El estudio sigue un tipo de análisis histórico del pensamiento científico que giró en torno a la categoría de análisis. Este análisis se hizo desde un enfoque interdisciplinar que permite interrogar de forma critica a los lenguajes disciplinares, en tanto discursos que son producidos por la ciencia y que contribuyen a la producción de la noción de infancia. Para eso se hizo el análisis de la revista Educación, publicada entre 1933 y 1935. La revista era utilizada como órgano de difusión de la Facultad de Ciencias de la Educación de la Universidad Nacional de Colombia.

\section{Procedimiento}

Se escogió a la revista Educación, por ser un corpus documental de carácter científico, en donde se manifestaban los esfuerzos de una política estatal de difusión de las ideas modernizadoras. En las páginas de ésta revista se evidencia una marcada preocupación por temas relacionados con la infancia, principalmente por la infancia popular que era descrita en "situación de riesgo" y que debería tener una indispensable "atención del Estado".

Para la presente investigación se escogieron 48 artículos que abordan los conceptos de infancia, inteligencia, pedagogía y psicología, en donde se demuestran los postulados epistemológicos, teóricos y las instituciones y autores que configuraban estos conceptos.

Los artículos se organizaron en tres categorías. Primero, los que tienen como tema central el rol del Estado en relación con la infancia y la promoción de reformas educativas; en ellos se busca aproximarnos a los comportamientos que la sociedad, especialmente la institucionalidad, buscaba tener frente a la infancia. Segundo, los artículos que en sus páginas se hace referencia a los procesos de la escuela activa y los conceptos de la psicología experimental en relación con la infancia. De ellos se puede obtener los métodos y conceptos que circularon, y a su vez, gestionaron para la constitución de las ideas e imágenes sobre la infancia. Tercero, los artículos que realizan una descripción de la operatividad de institutos en el exterior, bajo las premisas de la escuela activa, que servían de modelos para ser implementados en Colombia

Una vez escogidos los artículos, estos fueron abordados desde la perspectiva de análisis de textos de Chartier. Quien plantea la importancia de analizar al texto en relación con otros textos, cuya producción va más allá de una mera descripción. De esta forma en el texto se pueden encontrar los conceptos y obsesiones de sus productores. Para el autor, la relación del texto con la realidad (que tal vez podamos definir como aquello que el mismo texto plantea como real al construirlo en un referente fuera de sí mismo) se construye según modelos discursivos y divisiones intelectuales propias a cada situación de escritura. Lo real adquiere así un sentido nuevo: aquello que es real, en efecto, no es la realidad que apunta el texto, sino la forma misma en que lo enfoca dentro de la historicidad de su producción (Chartier, 2005).

\section{Resultados y Discusión \\ La Infancia: Un problema político}

Parte de los esfuerzos de los intelectuales con ideales modernos en la primera mitad del siglo XX, eran dedicados a hacer visible el desorden social y el atraso intelectual y económico en el que se encontraba la ciudadanía. La siguiente cita, muestra una opinión que tenía un cierto consenso en estos académicos y políticos, en los que se buscaba la mejor forma de orientar a la Nación.

Nuestros centros urbanos y muy especialmente la capital de la República, vienen exhibiendo y tolerando desde hace mucho tiempo un espectáculo escandaloso que deberían sonrojarnos ante la mirada del mundo civilizado: es ese pulular de niños haraposos, sin personas responsables que los vigile y los oriente, sin techo que los abrigue, sin pasado preciso, sin futuro cierto. Es como una falange de pequeños parias trashumantes, esta multitud de hijos del arroyo qzue mañana han de construir "la masa", para la cual se reclama la máxima intervención política.

La calle de nuestra ciudad es la escuela donde esa masa infantil hace en aprendizaje de la vida; y a fe que demuestra bastante precocidad en la organización de verdaderas bandas de apaches y rateros, en la astucia para el atentado contra la propiedad particular y en el empleo del léxico más rico que pueda exhibir diccionario de la indecencia. La crónica policiaca nos ilustra diariamente con el relato de las hazañas desarrolladas por las cuadrillas de los pequeños delincuentes. Para quien haya paseado por otros países y se haya puesto en contacto con la vida urbana de otros pueblos, este espectáculo de la adolescente vendedora de boletas de lotería, del rapazuelo que a altas horas de la noche se acerca a ofrecer el anillo robado, del hacinamiento de cuerpos de limpiabotas tiritando de frio sobre las duras piedras del dintel, del escalonamiento interminable de los niños pordioseros que a todas horas y en todos los sitios concurridos desarrollan su tenaz persecución a los transeúntes, todo esto es inmensamente lamentable y bochornoso, indigno de un pueblo culto (Bernal, 1934, p. 65). 
El "caos" descrito en la cita anterior, nos muestra una fotografía del malestar que existía por parte de un sector intelectual de la Nación con respecto a un grupo etario en particular, la infancia; pero no toda la infancia. La infancia a la cual nos referimos es la de la calle, la que vive en pobreza, la campesina, la que no se encuentra en las instituciones educativas modernas, la que está fuera del control del Estado. La infancia que no tiene vigilancia ni intervención del Estado, es señalada como una población en peligro que atentaba contra el desarrollo social del país; esta población era indigna de un pueblo culto. Se advierte una infancia en miseria y en desamparo, víctima de enfermedades y vicios.

Las características que se le atribuían a la infancia en peligro, extraído de la revista Educación son: (a) niños macilentos y descoloridos; (b) rebeldes, desobedientes, mentirosos; (c) desnutrido, mal vestido, de malas costumbres; (d) niños enfermos, (e) niños que sufren, (f) viven la vida de otras personas, (g) miseria fisiológica, (h) parasito de la civilización debido a la mezcla racial.

Entrada la década de los años 30 se mencionaba que en Colombia existían alrededor de 950.000 niños y niñas en edad escolar que no asistían a la escuela ni recibían educación de ninguna naturaleza. Esta cifra representaba aproximadamente las dos terceras partes de la población infantil de la República. Este porcentaje era atribuido a la falta de escuelas suficientes que dieran cuenta de la creciente población y resolviera el índice de analfabetismo que por ese mismo año estaba en un 56\%. Existían 7.012 escuelas primarias que alcanzaban acoger un número de 513.775 niños; es decir, que para la época se calculaba la necesidad de tener 15.000 escuelas en total, para recibir toda la población en edad escolar, a razón de sesenta estudiantes por maestro (Bernal, 1933, p. 129).

Según la legislación colombiana de 1904, que aún se encontraba en vigencia para el periodo de análisis, la enseñanza primaria debía impartirse en escuelas urbanas y rurales. La diferencia principal entre las categorías de establecimientos escolares estaba en su programa de estudio. La escuela urbana abarcaba seis años; dos años de estudios elementales, dos de estudios medios y dos de estudios superiores que preparaban en principio para el colegio secundario. La escuela rural no comprendía sino tres años de estudio. Casi la mitad de la población escolar, se encontraba en el primer año de escolaridad y más del $80 \%$ se hallaba concentrado en los dos primeros años de escuela, al concluir los cuales, era dudoso que hubieran alcanzado definitivamente la capacidad de leer y escribir. Según estadísticas de 1932, sólo el 7.5\% llegaba a los tres últimos años de enseñanza primaria, que daban posibilidades reales de ingresar en el sector secundario (Helg, 2001, p. 49).

Tal vez algún día, nuestros niños y nuestras niñas, volverán de la escuela rosados y valerosos, en vez de macilentos y descoloridos, y las escuelas satisfarán como no lo hacen ahora, al mismo tiempo al médico y al educador (...) por eso es necesario que estas escuelas posean un gran patio en donde los niños se entreguen a los ejercicios físicos y juegos, en los intervalos de las horas de trabajo (Gamboa, R., p. 1933, N², p. 88).

Hay que luchar contra la miseria fisiológica en la niñez, el pauperismo opresor, la detestable carencia de higiene, de expresión y de deportes físicos (Gaviria, 1933, p. 175).

Estas dos citas muestran algunas reflexiones que se hacían sobre la situación higiénica y fisiológica de los infantes tanto al interior como al exterior de las escuelas. Teniendo en cuenta estas variables, se promulgaba la necesidad de intervenir las escuelas con la creación de nuevos espacios que brindaran trato especial al desarrollo de la salud física. El Estado direccionaba parte de sus esfuerzos para que el médico y el educador se vincularan en la protección del infante en un lugar privilegiado como la escuela.

\section{La infancia desde la Psicología Experimental y la escuela a la medida}

El análisis de la revista Educación muestra con metódica regularidad a la psicología experimental como un discurso científico que legitima una serie de imágenes de la infancia, mostrándolos como válidos, científicos y objetivos; imágenes que se soportan en discursos provenientes de instituciones modernas y de expresiones tales como saberes "nuevos", renovación racial y nacional; teniendo como referente la cultura científica, tecnológica e institucional de Europa y los Estados Unidos.

La psicología experimental para los intelectuales con ideales modernos en Colombia, era apreciada como el análisis de los mecanismos mentales, en donde la biología y la sociología estudian las raíces biológicas y la evolución social de los fenómenos psíquicos, y en donde la psicología patológica y la patología mental depositan, mediante el examen de los trastornos elementales de este género y de la psicosis y sus condiciones cerebro-orgánicas, la contribución más precisa (Noguera, R., 1934, №8, p. 150-162).

Desde la perspectiva de la psicología experimental, se daba una ruptura con la psicología clásica. La psicología clásica era criticada por estar impregnada de moral, por crear imágenes de los infantes que no están relacionados con la "realidad", sino más bien, con las pretensiones que 
desde la moral, se busca que el hombre se constituya, a partir de su educación y socialización. Los modernos no rechazaban el principio de modificación del hombre, pero esta modificación la hacían a partir de lo que ellos llamaban como leyes propias para el funcionamiento biológico y mental. Para ello buscaban conocer la naturaleza humana, a partir de su constitución orgánica y hereditaria (Piéron, 1933).

Los desarrollos de la fisiología y la biología permitieron el surgimiento de la psicología como ciencia experimental. A partir de estos avances se crearon nuevos problemas para la psicología como la medida de intensidad de las sensaciones, la medida de las reacciones mentales, el estudio de las percepciones, $y$ de las funciones superiores como la memoria, la atención el poder de abstracción y la función generalizadora. El funcionamiento mental lo apreciaban en conjunto. La aptitud y la inteligencia se convierten en un constructo importante, por medio de su análisis, se buscaba dar orientación profesional a los infantes, con el objeto de colocar al hombre "donde corresponde" para bien fuese salvarlo del atraso físico e intelectual en el que se encontraba y/o para que prestase a la sociedad el máximo de sus servicios (Piéron, 1933).

La psicología experimental, en su fase cuantitativa, se podía entender desde la psicofísica o medida de la intensidad de las sensaciones; y desde la psicometría o medida de la duración de las reacciones mentales: percepción y volición, y reacciones simples o complejas. La fase cuantitativa se vería complementada por la antropometría mental, entendida como la rama de la biología que estudia la especie humana en el presente y el pasado. La antropometría consiste en análisis precisos, implica mediciones exactas, tanto anatómicas como fisiológicas, tomadas sobre el hombre vivo y el esqueleto. La antropometría mental constituye hoy el "método de los test" (Buyse, 1933a, p. 139).

A continuación, se cita parte de un artículo en el que se puede observar como el infante para las ciencias experimentales se convierte en un complejo psicofisiológico, como un conjunto de fuerzas orgánicas que al ser estimuladas por el ambiente, desarrolla sus capacidades y sus aptitudes.

(...) el conocimiento aun cuando sea somero de estos asuntos importantísimos (se refiere al conocimiento de los trabajos de los órganos incluyendo el cerebro) para el educador al fin de que tenga muy presente que la vida anímica e intelectual del niño, no obedece a determinadas modalidades, ni a la actividad de ciertos órganos, sino a la armonía integral del compuesto. Si tiene presente este postulado, su acción educativa no se concentrará al perfeccionamiento de ciertas facultades, sino que buscará constantemente el desarrollo y perfeccionamiento del niño todo, como ente de perfecta unidad pero que sufre la interdependencia cósmica con mucha mayor intensidad que los hombres ya formados (Benavides, 1933, p. 227).

La actividad orgánica debía ser conocida por los maestros ya que les proporcionaría una explicación del funcionamiento de la adquisición del conocimiento, orientando sus prácticas en las aulas de clase. De esta forma, se buscaba entender, potencializar y estar en armonía con aquello que la naturaleza había proporcionado a los niños.

Con esta nueva idea del funcionamiento de los principios más internos de explicación del conocimiento de la infancia, incorporada por la modernidad experimental, como lo señala Saldarriaga, O. (2003), se logra un nuevo nivel de subjetividad del infante, que se explica principalmente desde la fisiología. Desde la idea de garantizar la armonía integral de los compuestos orgánicos del infante, que promulgaba el método experimental, se genera una ruptura con la noción de conocimiento que en Colombia se daba desde Pestalozzi y la modernidad sustentada en la episteme clásica, en donde las facultades mentales o del alma, eran concebidas como operaciones discretas, aislables, casi como "fuerzas musculares" a las que había que ejercitar constantemente a partir de la voluntad.

Para los experimentalistas, detrás de todo fenómeno complejo, existe una cosa en extremo complicada: el organismo entero que funciona. De esta forma, el organismo en su integralidad, se convierte en un énfasis de estudio de la psicología experimental, que derivaría en entender al infante como un organismo psicofisiológico. La psicología empezó a explicar las cualidades del funcionamiento mental por medio de unas funciones definidas. Cuando juzgaban la inteligencia o la atención, lo hacían teniendo en cuenta las cualidades de su funcionamiento en conjunto y no de una función que pueda aislarse; el aprendizaje es abordado a partir del funcionamiento cerebral global y complejo; las aptitudes se estudiaban a partir de una cualidad práctica del funcionamiento mental y aún del funcionamiento orgánico general. Por lo tanto, se promulgaba el desarrollo de las diferentes funciones en un sentido armonioso (Piéron, 1933).

Sin embargo, la ruptura entre la modernidad experimental y la modernidad clásica no es tan evidente, porque los métodos experimentales continúan con la observación y el empirismo como fundamentos acogidos por la modernidad clásica que daban explicación del conocimiento. Lo que hace la experimentación, entre otras cosas, es incluir procedimientos artificiales que simulen los procesos naturales y de esta forma ir construyendo toda una estructura 
que le permitiera entender y controlar los mecanismos de aprendizaje, y de esta forma dar una explicación del funcionamiento de los mecanismos subjetivos del conocimiento desde la fisiología.

\section{Tres instituciones en el exterior: ejemplos tomados por los intelectuales con ideales modernos en Colombia}

El análisis de la historia de los saberes científicos que ayudaron a configurar las imágenes de la infancia, nos obliga a revisar las instituciones científicas, organizaciones, recursos y estatutos que regulaban la producción de conocimiento alrededor de la infancia. Por lo tanto, el siguiente apartado, tiene como objeto relacionar las instituciones que sirvieron como fundamento de una serie de conceptos y elaboraciones conceptuales, a los intelectuales con ideales modernos en Colombia. Desde estas instituciones, ubicadas principalmente en países europeos, producían conocimientos, que posteriormente eran puestos en circulación en Colombia.

Lo que encontraremos a continuación, son las metodologías utilizadas en lugares estratégicos, que tenían como pretensión hacer lectura del funcionamiento de la infancia, de su naturaleza y de su organismo. En ellos se buscaba la explicación de la relación psique-órgano, la cuantificación del funcionamiento de las facultades y la deducción de hipótesis que dieran explicación a las causas de los "males" de la infancia.

\section{Laboratorio de Angleur}

El laboratorio se encontraba en la ciudad de Angleur - Bélgica, a pocos kilómetros de la ciudad de Lieja. Estas instituciones se constituían en una novedad, no por su aparición, ya que desde 1867, funcionaban laboratorios similares en países como Estados Unidos, Alemania, PoIonia, Rusia, Italia y algunos países de América del Sur. Lo llamativo de este laboratorio era que estaba situado en la propia escuela primaria, buscando obtener conclusiones que prometieran mayor efectividad en el tratamiento de la infancia (Peña, G., 1934, № 11, p. 348-351).

El laboratorio tenía como objetivo el estudio del niño y de los sistemas pedagógicos, procurando avanzar en los estudios científicos que se desarrollaban alrededor de la infancia. Desde esta institución se observaban los comportamientos de la infancia, se recopilaba y sistematizaba la información para el personal docente, como metodología que facilitaba la clasificación científica de los grupos de infantes. Una vez clasificados y diagnosticados, personal médico y pedagógico tenía como tarea determinar las causas de los males clasificados y proponer los remedios del caso. Para hallar las soluciones a los problemas señalados desde el análisis de observación, en el laboratorio se realizaban experimentos y se ponía en uso del método estadístico, tendientes a solucionar el mal y las causas que lo originaban (Peña, 1934).

Entre las técnicas de observación implementadas en el laboratorio se encontraban el examen que se hacía al inicio del año escolar a todo estudiante; en el trascurso del año se llenaban fichas individuales que comprendían seis páginas en donde se trataban ocho cuestiones diferentes como la encuesta familiar y social, antecedentes personales, examen médico, examen de los sentidos y de los dientes, examen motor, examen de la inteligencia, de la afectividad y examen pedagógico (Peña, 1934).

Desde estas fichas, se propendía que el maestro tuviese conocimiento de sus estudiantes, darles herramientas pedagógicas y métodos disciplinares para la enseñanza de acuerdo a la psicología de cada niño, buscaban seguir la evolución psique-órgano y establecer las causas de los retrasos intelectuales (Peña, 1934).

\section{La Maison des Petits}

Otra de las Instituciones referentes y modelos a seguir en Colombia era la Maison des Petits de Suiza, calificada como una escuela que implementaba todos los métodos experimentales existentes que permitieran el desarrollo físico, social y moral del niño. En esta institución, la maestra, en el primer mes, media y observaba la fuerza y desarrollo de cada uno de los alumnos: la capacidad auditiva, visual, táctil, muscular, etc., al mismo tiempo que aplicaba el test de inteligencia. En esta forma la maestra se da cuenta del estado intelectual de sus alumnos para no exigirles un trabajo superior a sus capacidades, como no se le exigiría a una máquina un rendimiento superior a su potencialidad (Zapata, 1933, p. 170).

Paralelamente se hacía un ejercicio de observación de las actividades espontaneas, con el objeto de establecer cuáles son las orientaciones de los niños, qué juegos les gusta, con quién habla más, qué tipo de instrucciones sigue; el maestro tenía como función tratar de ver qué de esa orientación es lo que más atención llamaba del niño. Se utilizaban los relatos históricos con el objeto de encausar alguna actividad, pero siempre sin una dirección determinada; se utilizaba el dibujo como herramienta para analizar la originalidad, la personalidad, los sentimientos artísticos y reconocer el gusto por el color y los progresos de los niños en esta materia. En cada salón existían juegos y materiales, de esta forma el niño escogía el que me atrajera: plastilina para hacer modelado; tablitas de diferentes formas y colores, para hacer figuras; juegos de construcción, que 
sometían al niño a la disciplina del movimiento, de ojo y de raciocinio (Zapata, 1933, p. 172).

Los profesores impedían la influencia de los unos con los otros y así garantizaban que sus acciones fuesen libres, y ellos pudieran tener un concepto más acertado y seguro sobre cada uno. Algunos perseveraban en su trabajo, en cuanto que otros lo abandonaban para buscar nuevas impresiones. Cuando un niño insistía demasiado en hacer una sola cosa, la maestra inmediatamente buscaba la causa y lo clasificaba de acuerdo con las otras observaciones que sobre él había hecho.

De esta forma, la institución promovía el conocimiento de la actividad, los gustos, las aptitudes y necesidades de los niños, con el objeto de encausarlos, obteniendo de ello una economía del tiempo, de materiales y de actividades.

\section{Una escuela en Bruselas}

Entre las visitas de estudiantes que eran enviados a expediciones al exterior, se referenciaba una escuela en Bruselas, que quedaba hacia las afueras del centro poblacional. Esta escuela, aunque dedicada principalmente a niños retardo, reunía las características de la pedagogía activa y era modelo en cuanto a sus metodologías para el Estado colombiano.

La escuela se ubicaba en un edificio pequeño en donde funcionaba el despacho del director, la biblioteca, los materiales de trabajo y una sala de recibo. La escuela estaba a cargo de un director general que no manejaba grupo y que tenía como deberes el atender a la marcha de la enseñanza; revisar los trabajos de los maestros; darle nuevas orientaciones; estudiar con el médico y las enfermeras el estado físico de los alumnos; hacer los exámenes mentales para la clasificación del personal y formación de las fichas individuales; atender a los interesados y dar las informaciones; visitar a las familias para mejor dirección de los niños; congregar a los padres quincenalmente para enterarlos de los trabajos; reunir semanalmente a los maestros para estudiar puntos especiales y corregir las deficiencias; llevar un cuadro completo con los datos antropométricos, físicos, psicológicos y sociales para los informes de los padres; examinar diariamente el plan de trabajos de los maestros y renovar el examen psicológico cada seis meses (Jaramillo, 1933, p. 231).

El máximo de alumnos por grupo, es de quince para las escuelas especiales y de veinticinco para las ordinarias. A parte de la ficha que lleva la escuela, cada niño lleva su carné de peso y talle en donde anota mensualmente su progreso o deficiencia, lo cual lo conduce a un interés personal por su desarrollo (Jaramillo, 1933, p. 231).
La enseñanza tiene un objetivo vital por cuanto procura acomodarse a los intereses infantiles. Parte de sus gustos a las relaciones. Del juego y de sus preocupaciones habituales, sus capacidades son enderezadas al desenvolvimiento armónico sensorial e intelectual. En todos los grupos se dispone de materiales abundantes y variados, que los mismos niños construyen en los trabajos manuales. Las figuras de las revistas y de los catálogos comerciales constituyen medios para interesantes trabajos con las apreciaciones de forma, tamaño, color, medida; alrededor de ellas se hace frases para la lectura, y son adheridas a los cuadernos; en los trabajos manuales las imitan en cartón, arcilla, plastilina, tela, madera, etc. (Jaramillo, 1933, p. 231).

En cada salón se encontrará una balanza utilizable para los cálculos del peso, lo que da material para considerables combinaciones vividas. Los juegos de lotería y la reconstrucción de cuadros divididos, son motivos para desarrollar la atención. La música, el canto, la danza, la gimnasia rítmica, las dramatizaciones, aparte de la educación del oído y de la formación artística, son acostumbrados para mantener la alegría escolar. El registro diario de la temperatura y las variaciones del tiempo, los procesos de germinación, el cuidado de animales de la escuela atrae al niño y lo habitúan a reparar en todo lo que la naturaleza le ofrece continuamente (Jaramillo, 1933, p. 231).

En un ambiente de participación directa del niño, la escuela delinea su personalidad. El sólo registro de su salud lo induce a sus propios cuidados higiénicos (Jaramillo, 1933, p. 231).

\section{Consideraciones Finales}

En este texto se puede observar que los intelectuales con ideales modernos ponen en circulación unos conceptos, discursos y/o lenguajes que hacen visibles las particularidades de la infancia. Con ellos emerge una infancia moderna y activa, que desde su movimiento y actuar sobre el mundo, desarrolla sus facultades mentales; que entra en un procesual desarrollo y se convierte en el eje fundamental de transformación de la sociedad moderna. Se tiene la impresión que, desde la primera mitad del siglo $X X$, es en donde este infante se hace visible, sale a la luz por primera vez y se convierte en objeto de conocimiento; sin embargo, es necesario volver al análisis: con la irrupción del método experimental son las formas del lenguaje sobre la infancia las que se reorganizan, acentuando e incorporando nuevos elementos a su imagen.

Decimos que acentúa en el sentido que da fuerza a la idea de un infante activo, desde donde se funda lo singular del mecanismo del conocer en la infancia, y por este camino hacer del niño un objeto de conocimiento. 
En esta vía, es el método pestalozziano el que sienta las bases, desde la teoría de la sensación, para generar una reforma que derive hacia una práctica más activa en las formas de adquisición de conocimiento del infante, la experiencia como forma de conocimiento en el niño. Mencionamos que incorpora elementos a la imagen de la infancia, porque al dar un suelo epistemológico desde la fisiología y la biología, se da una explicación nueva a los mecanismos subjetivos y el infante aparece como un complejo psicofisiológico, un objeto de medición y como una etapa de extrema fragilidad y cuidado.

Para que la infancia fuera posible como forma de conocimiento, ha sido menester toda una reorganización de los saberes sociales, la escuela y la familia. Muestra de ello, es el vuelco de los saberes sociales a la experimentación, la intencionalidad de convertir a las escuelas en laboratorios psicológicos. Es decir, parte de la definición de la infancia desde la sociedad, se ha debido al proceso de envoltura del infante en un espacio cerrado como la escuela. Con ello hubo una definición nueva del estatuto del infante en la sociedad.

Es esta estructura en donde se articula lo político, lo académico, lo cultural y el lenguaje experimental; en donde se constituye lo que históricamente llamaríamos la infancia como un grupo particular desde el orden fisiológico, como un objeto de medición y un sujeto de extrema fragilidad. En otras palabras, la infancia como un objeto positivo, digno de ser examinado, tratado, puesto a prueba y a medida; al que se puede dominar y controlar. Estas imágenes, permitieron que la estructura de la sociedad estableciera todo un ejercicio de gobierno y administración de la infancia, en donde ésta se vinculara a los criterios administrativos establecidos por el Estado.

Los discursos experimentales tuvieron una incidencia importante en la forma como vemos y nos relacionamos con los infantes. Esta investigación se une a todas aquellas, que demuestran que la infancia es un producto histórico moderno y no es un dato general y un producto natural. La infancia es una construcción social reciente.

\section{Referencias}

Benavides Campo, M. (1933). Localización de las facultades intelectivas. Educación, 4, 226- 229.

Bernal, R. (1933). Los proscritos de la escuela. Educación, 3, 129-133.

Bernal, R. (1934). Los niños parias. Educación, 7, 65-68.

Buyse, R. (1933a). Estudio crítico sobre los orígenes de la Pedagogía Moderna (I). Educación, 3, 134-146. Gamboa, R. (1933). Escuela al aire libre. Educación, 2, 88-92.
Gaviria, N. (1933). El ambiente pedagógico y Colombia. Educación, 3, 173-175.

Jaramillo, A. (1933). Organización de una Escuela en Bruselas. Educación, 4, 230-235.

Noguera, R. (1934). Conciencia e introspección (I). Educación, 8, 150-162.

Peña Martínez, G. (1934). Una visita al laboratorio de Angleur. Educación, 11, 347-351.

Piéron, H. (1933). Las aptitudes en la escuela. Educación, 2, 70-81.

Zapata, L. (1933). La Maison des Petits. Educación (3), 169172.

Fuentes Secundarias

Ariès, P. (1987). El niño y la vida Familiar en el antiguo régimen. Madrid: Taurus.

Bernstein, B., \& Díaz, M. (1984). Hacia una teoría del discurso pedagógico. CORE, 8-(3).

Bourdieu, P. (1997). Razones prácticas, sobre la teoría de la acción. Barcelona: Anagrama.

Braunstein, N. (1975). ¿Cómo se constituye una ciencia? En N. A. Braunstein., M. Pasternac,. Benedicto, \& F. Saal (Eds.). Psicología: ideología y ciencia.(pp.7-46). México D.F: Siglo Veintiuno Editores.

Burke, P. (2000). Formas de historia cultural. Madrid: Alianza Editorial.

Burke, P. (2000). Historia social del conocimiento. De Gutenberg a Diderot. Barcelona: Paidós.

Burke, P. (2004). ¿Qué es la historia cultural? Barcelona: Paidós.

Caballero, A. (1932). El Doctor Decroly en Colombia. Bogotá: Imprenta Nacional.

Carli, S. (2006). La cuestión de la infancia. Entre la escuela, la calle y el shopping. Buenos Aires: Paidós.

Chartier, R. (2005). El mundo como representación. Estudios sobre historia cultural. Barcelona: Gedisa.

Chartier, R. (1993). Libros, lecturas y lectores en la edad moderna. Madrid: Alianza.

Claparède, E. (1923). Cómo diagnosticar las aptitudes en los escolares. Paris: Ernest Flammarion.

Díaz S., C. J., Amador, J. C., \& Delgadillo C., I. (2010). La tentación de la inocencia. Niños, niñas y jóvenes excombatientes. Análisis de sus narraciones. Estudio exploratorio. En C. J. Díaz S., J. C. Amador, I. Delgadillo C., \& O. Silva Briceño (Eds.). Emergencia de la memoria. Dos estudios sobre la infancia, la escuela y la violencia (pp. 17-140). Bogotá: Universidad Distrital Francisco José de Caldas.

Díaz, C. J. (2010). Más allá de la infancia escolarizada: Elementos para una discusión sobre el campo investigativo de las infancias. Pedagogías y saberes, 37, 49-62.

Díaz, C.J. (2010). (en prensa) Política del conocimiento. Las infancias: categoría conceptual y objeto de conocimiento.

Durkheim., E. (1993). Las formas elementales de la vida religiosa. Madrid: Alianza. 
Elías, N. (1994). Conocimiento y poder. Madrid: La Piqueta.

Elias, N. (1998). La civilización de los padres y otros ensayos. Bogotá: Norma.

Elkana, Y. (1983). La ciencia como sistema cultural: Una aproximación antropológica. Boletín Sociedad Colombiana de Epistemología, 65-80.

Foucault, M. (1968). Las palabras y las cosas. Una arqueología de las ciencias humanas. Buenos Aires: Siglo Veintiuno Editores.

Foucault, M. (1970). El orden del discurso. Buenos Aires: Siglo Veintiuno Editores.

Foucault, M. (1979). Microfísica del poder. Madrid: La Piqueta.

Foucault, M. (1976). Vigilar y castigar. Buenos Aires: Siglo Veintiuno Editores.

Foucault, M., Donzelot, J., Grignon, C., de Gaudemar, J.P., Muel, F. \& Castel, R. (1991). Espacios de poder. Madrid: La Piqueta.

Fried Schnitman, D. (1998). Ciencia, cultura y subjetividad. En D. Fried Schnitman. Nuevos paradigmas, cultura y subjetividad (p. 15-36). Buenos Aires: Paidós.

Glasersfeld, E. V. (1998). Introducción al constructivismo radical. En P. Watzlawick. La realidad inventada ¿Cómo sabemos lo que creemos saber? (p. 17-37). Barcelona: Gedisa.

González, F. (2002). Sujeto y subjetividad, una aproximación histórico cultural. México, D.F.: Thomson.

Helg, A. (2001). La educación en Colombia:1918-1957. Bogotá: Plaza \& Janez.

Herrera, M.C. \& Díaz Soler, C. J. (2001). Educación y cultura política: Una mirada multidisciplinaria. Bogotá: Plaza \& Janés.

Hobsbawm, E. (1991). Naciones y nacionalismos desde 1780. Barcelona: Crítica.

Ila, P.A. (2011). Recordar la infancia en el siglo XX. En J. Borja Gómez y P. Rodríguez Jiménez, Historia de la vida privada en Colombia. Tomo II (p. 235-261). Bogotá: Taurus.

Jiménez, A. (2008). Infancia y ciudad en Bogotá. Una mirada desde las narrativas populares urbanas. Bogotá: Universidad Francisco José de Caldas.

López, G. C., Ariza Cobo, A. \& Bujanda Bujanda, M. E. (1999). El Sistema de investigación educativa en España. Madrid: Secretaría General Técnica-Ministerio de Educación, Cultura y Deporte.

Marín, E. (1998). La noción de sujeto. En D. Fried Schnitman. Nuevos paradigmas, cultura y subjetividad. (p. 6785). Buenos Aires: Paidós.

Muñoz, C. \& Pachón, X. (1991). La niñez en el siglo XX. Salud, educación, familia, recreación, maltrato, asistencia y protección. Bogotá: Planeta.

Narodowski, M. (1994). Infancia y poder. La conformación de la pedagogía moderna. Buenos Aires: Aique.

Peña, Correal, T. E. La psicología en Colombia: historia de una disciplina y una profesión. En C. Instituto Colombiano para el Desarrollo de la Ciencia y la Tecnología Francisco José de Caldas. Historia Social de la Ciencia en
Colombia. Bogotá: COLCIENCIAS, 1993 p. 1-62.

Popkewitz, T. S. (2001). La producción de la razón y el poder: historia del currículum y tradiciones intelectuales. En M. E. Aguirre Lora. Rostros históricos de la educación miradas, estilos, recuerdos (p. 97-139). México, D.F.: Fondo de Cultura Económica.

Popkewitz, T. S. (2003). La producción de la razón y poder: historia del currículum y tradiciones intelectuales. En T. S. Popkewitz, B. M. Franklin, \& M. A. Pereyra. Historia cultural y educación. Ensayos críticos sobre conocimiento y escolarización (p. 147-184). Barcelona: Pomares.

Popkewitz, T.S., Pereyra, M. A., \& Franklin, B. M. (2003). Historia, el problema del conocimiento y la nueva historia cultural de la escolarización: Una introducción. En T. S. Popkewitz, M. A. Pereyra, \& B. M. Franklin. Historia cultural y educación. Ensayos críticos sobre conocimiento y escolarización (p. 15-58). Barcelona: Pomares.

Quinceno Castrillon, H., Sáenz Obregon, J., \& Vahos, L. A. (2004). La instrucción y la educación pública en Colombia: 1903-1997. En O. L. Zuluaga Garcés, \& G. Ossenbach Sauter, Modernización de los sistemas educativos iberoamericanos Siglo XX (p. 105 170). Bogotá: Magisterio.

Rodríguez, W. (1993). Orígenes. En R. Ardila, Psicología en Colombia: Contexto social e histórico (págs. 25-40). Bogotá: Tercer Mundo Editores.

Rousseau, J. J. (1762). Emilio o de la Educación. Bogotá: Ediciones Universales.

Sáenz Obregon, J., Saldarriaga, O., \& Ospina, A. (1997a). Mirar la infancia: pedagogía, moral y modernidad en Colombia, 1903-1946 (Vol. 1). Medellín: Foro Nacional por Colombia, Colciencias, Uniandes, Universidad de Antioquia/Clio.

Sáenz Obregon, J., Saldarriaga, O., \& Ospina, A. (2003). Las ciencias humanas y la reorientación de la pedagogía. En J. Sáenz Obregón, Psicología y pedagogía en la primera mitad del siglo XX. Madrid: G. Ossenbach, págs. 1-27

Sáenz Obregon, J. (05 de noviembre de 2004). Psicología y escuela activa en Colombia. Bogotá, Cundinamarca, Colombia: Foro Nacional por Colombia.

Saldarriaga, O. (2003). Del oficio de maestro, prácticas y teorías de la pedagogía moderna en Colombia. Bogotá D.C: Editorial Magisterio.

Sánchez Botero, C. H. (2009). Ciencia y educación superior en la República Liberal. En R. Sierra Mejía, República Liberal: Sociedad y cultura (p. 519-556). Bogotá: Universidad Nacional de Colombia.

Saussure, F. Curso de lingüística general. Bogotá: Skla,1916.

Serna Dimas, A. (2006). Saberes educativos y saberes sociales: esbozo para una historia social de sus estructuras institucionales. En J. Gómez Esteban, H. Lara Romero, M. J. PáezMadera, L. M. Parada M, C. Piedrahita Echandía, A. Serna Dimas, O. Useche (Eds.), Estructura tiempo y sujeto. Nuevos recursos para la discusión interdisciplinaria (pp. 101-146). Bogotá: Fondo de Publicaciones Universidad Francisco José de Caldas. 
Serna Dimas, A. (2007). Documento e interdisciplinariedad. El documento: realidad, reflejo y producción. En F. Bravo Leon, L. M. Parada Muñoz, \& A. Serna Dimas, La cuestión interdisciplinaria. De las cuestiones epistemológicas a los imperativos estratégicos para la investigación social (p. 127-142). Bogotá: Universidad Distrital Francisco José de Caldas.

Serna Dimas, A. (2006). Estructura tiempo y sujeto. Nuevos recursos para la discusión interdisciplinaria. Bogotá: Fondo de Publicaciones Universidad Francisco José deCaldas. Silva, R. (2005). República liberal, intelectuales y cultura popular. Medellín: La Carreta Histórica

Wallerstein, I. (2006). Abrir las ciencias sociales. Madrid: Siglo XXI de España editores, s.a.

Watzlawick, P y otros. (1998). La realidad inventada. Barcelona: Gedisa.

Zuleta, E. (19 de agosto de 2011). Proceso de desnaturalización. Medellín, Bogotá. 